\title{
Future of stereotactic intervention in lung cancer
}

\author{
Karin S. Kapp
}

Received: 30 November 2012 / Accepted: 11 December 2012 / Published online: 15 January 2013

(C) Springer-Verlag Wien 2012

\begin{abstract}
With the recent advances in technology, highly sophisticated hardware (linear accelerators specially designed for Stereotactic Radio-Surgery or Stereotactic Body Radiation Therapy (SBRT) using novel image guidance prior to and during the procedure) and equally sophisticated planning treatment software (static and dynamic Intensity Modulated Radiation Therapy) became available, allowing for ablative doses to be delivered with an accuracy of less than $1 \mathrm{~mm}$ to targets which are non-static due to respiratory motion.
\end{abstract}

With the recent advances in technology, highly sophisticated hardware (linear accelerators specially designed for Stereotactic Radio-Surgery or Stereotactic Body Radiation Therapy (SBRT) using novel image guidance prior to and during the procedure) and equally sophisticated planning treatment software (static and dynamic Intensity Modulated Radiation Therapy) became available, allowing for ablative doses to be delivered with an accuracy of less than $1 \mathrm{~mm}$ to targets which are non-static due to respiratory motion.

SBRT in lung cancer was originally investigated in patients who were unfit to undergo curative surgery on the grounds of coexisting serious medical problems mostly emphysema, heart disease, or diabetes [1, 2]. These patients often present with poor pulmonary function which not only precludes lobectomy/pneumectomy but also curative external beam irradiation (EBRT) due to the large volume of doses which are far beyond lung tissue tolerance. In the past these functionally inoperable patients were either treated with EBRT using moderate doses which yielded poor local control or received no local therapy at all.
Early results of SBRT in this vulnerable subset of patients have, across all borders, consistently shown its feasibility and its efficacy not only in terms of primary tumor control but also in survival, which has more than doubled when compared to the results achieved with conventionally fractionated "curative" EBRT.

Meanwhile, several Phase II studies have confirmed these promising results with 3 -year primary tumor control rates as high as $97.6 \%$ and 3-year survival rates of $55.8 \%$ in patients with peripheral stage T1-T2 N0 M0 non-small-cell lung cancer (NSCLC) less than $5 \mathrm{~cm}$ who were deemed inoperable due to their underlying medical conditions $[3,4,5]$.

It has to be stressed, however, that these highly encouraging results were obtained from carefully designed studies and participating centers, in which the necessary advanced technology with highly trained radiation oncologists, medical physicists, and radiation technologists was available-a definite prerequisite for SBRT.

For selected patients with peripheral NSCLC with lesions less than $5 \mathrm{~cm}$ who are unfit or unwilling to undergo lobectomy/pneumectomy, SBRT offers primary tumor control and survival rates that cannot be met with conventional irradiation doses and techniques. These patients should be offered SBRT and referred to centers, which are equipped to meet all the above mentioned demands.

For operable patients with early stage NSCLC, surgery remains the gold standard. This domain, however, is being challenged by a prospective study which randomizes potentially operable patients between surgery and SBRT [6]. The outcome of this study is awaited with great anticipation [7]. In case both approaches are proven equally effective, SBRT as a non-invasive procedure may serve as a true alternative to surgery. 


\section{References}

1. Wulf J, Haedinger U, Oppitz U, Thiele W, Mueller G, Flentje M. Stereotactic radiotherapy of primary lung cancer and pulmonary metastases: a non-invasive treatment approach in medically inoperable patients. Int J Radiat Oncol Biol Phys. 2004;60(1):186-96.

2. Nagata Y, Takayama K, Matsuo Y, Norihisa Y, Mizowaki T, Skamoto T, Sakamoto M, Mitsumori M, Shibuya K, Araki N, Yano S, Hiraoka M. Clinical outcomes of a phase I/II of $48 \mathrm{~Gy}$ of stereotactic body radiotherapy in 4 fractions for primary lung cancer using a stereotactic body frame. Int J Radiat Oncol Biol Phys. 2005;63(5):1427-31.

3. Timmermann R, Paulus R, Galvin J, Michalski J, Straube W, Bradley J, Fakiris A, Bezjak A, Videtic G, Johnstone D, Fowler J, Gore E, Choy H. Stereotactic body radiation therapy for inoperable early stage lung cancer. JAMA. 2010;303(11):1070-6.
4. Nagata Y, Wulf J, Lax I, Timmermann R, Zimmermann F, Stojkovski I, Jeremic B. Stereotactic radiotherapy of primary lung cancer and other targets: results of consultant meeting of the international atomic energy agency. Int J Radiat Oncol Biol Phys. 2011;79:660-9.

5. Martin A, Gaya A. Stereotactic body radiotherapy: a review. Clin Oncol. 2010;22:157-72.

6. ACOSOG Z4099/RTOG1021. Randomized phase III study of sublobar resection (+/- brachytherapy) versus stereotactic body radiation therapy in high risk patients with stage I non-small cell lung cancer (NSCLC). 2011. http:// www.acosog.org. Accessed 28 Nov 2012.

7. Timmerman RD. Surgery versus stereotactic body radiation therapy for early-stage lung cancer: who's down for the count? J Clin Oncol. 2010;28(6):907-9. 